\title{
Use of Platelet-Rich Fibrin Associated with Xenograft in Critical Bone Defects: Histomorphometric Study in Rabbits
}

\author{
Paulo Wilson Maia ${ }^{1}$, Marcelo Lucchesi Teixeira ${ }^{1}$, Luís Guilherme Scavone de Macedo ${ }^{1}$, \\ Antonio Carlos Aloise ${ }^{1}$, Celio Amaral Passos Junior ${ }^{1}$, Juan Manuel Aragoneses ${ }^{2}$, \\ José Luis Calvo-Guirado ${ }^{3}$ id and André Antonio Pelegrine ${ }^{1, *(D)}$ \\ 1 Faculdade São Leopoldo Mandic, Instituto de Pesquisas São Leopoldo Mandic, Campinas 13045-755, Brazil; \\ pwmaia@yahoo.com.br (P.W.M.); marceloltx@gmail.com (M.L.T.); drluismacedo@yahoo.com.br (L.G.S.d.M.); \\ aca.orto@uol.com.br (A.C.A.); cellioamaral@gmail.com (C.A.P.J.) \\ 2 Department of Dental Research in Universidad Federico Henríquez y Carvajal (UFHEC), \\ 10107 Santo Domingo, Dominican Republic; jmaragoneses@gmail.com \\ 3 Department of Oral and Implant Surgery, Faculty of Health Sciences, Universidad Católica San Antonio de \\ Murcia (UCAM), 30107 Murcia, Spain; jlcalvo@ucam.edu \\ * Correspondence: andre.pelegrine@slmandic.edu.br; Tel.: +55-19-981737532
}

Received: 20 September 2019; Accepted: 11 October 2019; Published: 15 October 2019

\begin{abstract}
Platelet-rich fibrin (PRF) is an autologous material used to improve bone regeneration when associated with bone grafts. It affects tissue angiogenesis, increasing the healing process and, theoretically, presenting potential to increase bone neoformation. The aim of this study was to verify, histomorphometrically, the effects of the association of PRF to a xenograft. Twelve adult white New Zealand rabbits were randomly assigned into two groups containing six animals each. After general anesthesia of the animals, two critical defects of $12 \mathrm{~mm}$ were created in the rabbit calvaria, one on each side of the sagittal line. Each defect was filled with the following biomaterials: in the control group (CG), xenograft hydrated with saline solution filling one defect and xenograft hydrated with saline solution covered with collagen membrane on the other side; in the test group (TG), xenograft associated with PRF filling the defect of one side and xenograft associated with PRF covered with collagen membrane on the other side. After eight weeks the animals were euthanized and a histomorphometric analysis was performed. The results showed that in the sites that were covered with collagen membrane, there was no statistically significant difference for all the analyzed parameters. However, when comparing the groups without membrane coverage, a statistically significant difference could be observed for the vital mineralized tissue (VMT) and nonmineralized tissue (NMT) parameters, with more VMT in the test group and more NMT in the control group. Regarding the intragroup comparison, the use of the membrane coverage presented significant outcomes in both groups. Therefore, in this experimental model, PRF did not affect the levels of bone formation when a membrane coverage technique was used. However, higher levels of bone formation were observed in the test group when membrane coverage was not used.
\end{abstract}

Keywords: fibrin; platelets; bone graft; bone regeneration; bone tissue

\section{Introduction}

Among the determining conditions for implant placement in their ideal prosthetic position, the presence of sufficient bone volume is still a determining factor for surgeons [1,2]. In such cases where this volume is insufficient, procedures for bone tissue reconstruction have been described in the literature with satisfactory results by guided bone regeneration technique or onlay block bone 
grafts. For adequate bone regeneration, the presence of viable bone cells is mandatory and, therefore, if the recipient bed cannot provide these cells to the graft material, it must contain viable bone cells by itself [3]. In this scope, autogenous bone grafts are still considered the gold standard for such procedures, in view of their biological potential (i.e., osteogenic, osteoinductive, and osteoconductive properties). However, the disadvantages associated with the procedure for harvesting grafting material have led professionals to seek new alternatives for bone reconstruction [4]. Time of procedure and postoperative discomfort, such as pain, edema, and bleeding, are some of the reported morbidity issues. Moreover, the amount of tissue available in the donor region and the quality can significantly influence the final outcome of the reconstruction [4]. Due to these factors, the search for substitute materials that could conduct bone formation has increased significantly.

Different biomaterials have been described as alternatives for autogenous bone, such as allogeneic, xenogeneic, and synthetic bone grafts [5]. However, the possibility of immunological reactions and the quality of newly formed tissue have been the subject of discussion due to their low density, compromising, in some clinical situations, the initial stability of implants and consequently, osseointegration [6]. The association of xenogeneic biomaterials with bone marrow-derived stem cells in reconstruction of critical defects has shown good results in experimental animal models with satisfactory vital mineralized tissue formation $[7,8]$. Similar associations performed in maxillary sinus floor elevation and horizontal bone augmentation procedures demonstrated better results in the formation of a vital mineralized tissue $[9,10]$. Nowadays, the nanotechnology is also collaborating with the tissue engineering field by developing more adequate scaffolds that can be associated with stem cells and signaling molecules. This triad has a high potential for several types of tissue construction [11]. However, the method of collecting and processing such cells is considered critical and high cost, which does not always make it possible to be performed in a clinical environment.

In contrast with stem cells approaches, platelet-rich fibrin (PRF) represents a simple "chair side" technique of platelet concentrates, first described in the literature to improve tissue regeneration and accelerate the healing process in surgical procedures [12-14]. It consists of a dense fibrin network, after collecting peripheral blood by simple venipuncture, containing leukocytes and platelets, which secrete important growth factors for the regenerative process, such as platelet-derived growth factor (PGDF), vascular endothelial growth factor (VEGF), and transforming growth factor beta (TGF- $\beta$ ). These growth factors act in the processes of angiogenesis, reepithelization, and extracellular matrix formation. Some studies report that such growth factors may be released over a period of up to 28 days. In addition, important adhesive proteins such as fibronectin and vitronectin are also secreted in PRF concentrates [12]. Regardless, studies have shown the possibility of associating PRF with bone substitute biomaterials $[13,14]$; the association of xenogeneic grafts with PRF in bone reconstructions of critical defects is scarce in the literature. Thus, the aim of this study was to analyze the association of platelet-rich fibrin with xenogeneic graft in critical defects in rabbit calvaria through histomorphometric evaluation. The null hypothesis of the present study is that the use of PRF would not result in higher levels of bone formation.

\section{Materials and Methods}

Twelve adult male New Zealand rabbits between 10 and 12 months of age, with an average weight of $3.5 \mathrm{~kg}$, were selected. The animals were adapted for the environment and then kept in individual cages with controlled temperature between $18^{\circ} \mathrm{C}$ and $20^{\circ} \mathrm{C}$ and food and water ad libitum. In all animals, general anesthesia was induced by ketamine $(40 \mathrm{mg} / \mathrm{kg})$, midazolam $(2 \mathrm{mg} / \mathrm{kg})$, and fentanyl citrate $(0.8 \mathrm{mg} / \mathrm{kg})$. Maintenance was performed by a mixture of (isoflurane $/ \mathrm{N}_{2} \mathrm{O}$ [1:1.5\%]):oxygen [2/3:1/3] using a pediatric laryngeal mask airway. This study was analyzed and approved by the Research Ethics Committee of the São Leopoldo Mandic Dental School, Campinas, SP, Brazil (process 0191/14). 


\subsection{Experimental Design}

Two circular critical bone defects were performed using a $12 \mathrm{~mm}$ external diameter trephine drill (Neodent, Brazil) in the calvaria of the 12 rabbits, totaling 24 defects, distributed in two groups: test group (TG) $n=6$, in which the mixture of platelet-rich fibrin (PRF) and xenograft was used as filler; and control group (CG) $n=6$, in which only saline solution was used in association with xenograft to fill the defects. The animals were randomly inserted in CG or TG using the tool provided in the website www.randomization.com. The biomaterials used in this study were: Bio-Oss ${ }^{\circledR}$ (Geistlich Biomaterials, Wolhusen, Switzerland) xenograft, a particulate bovine mineral matrix with granules between $0.25 \mathrm{~mm}$ and $1 \mathrm{~mm}$; Bio-Gide ${ }^{\circledR}$ (Geistlich Biomaterials, Wolhusen, Switzerland), a porcine resorbable bilaminar collagen membrane; and platelet-rich fibrin, obtained from the centrifugation of the autologous blood of each animal (Figure 1).

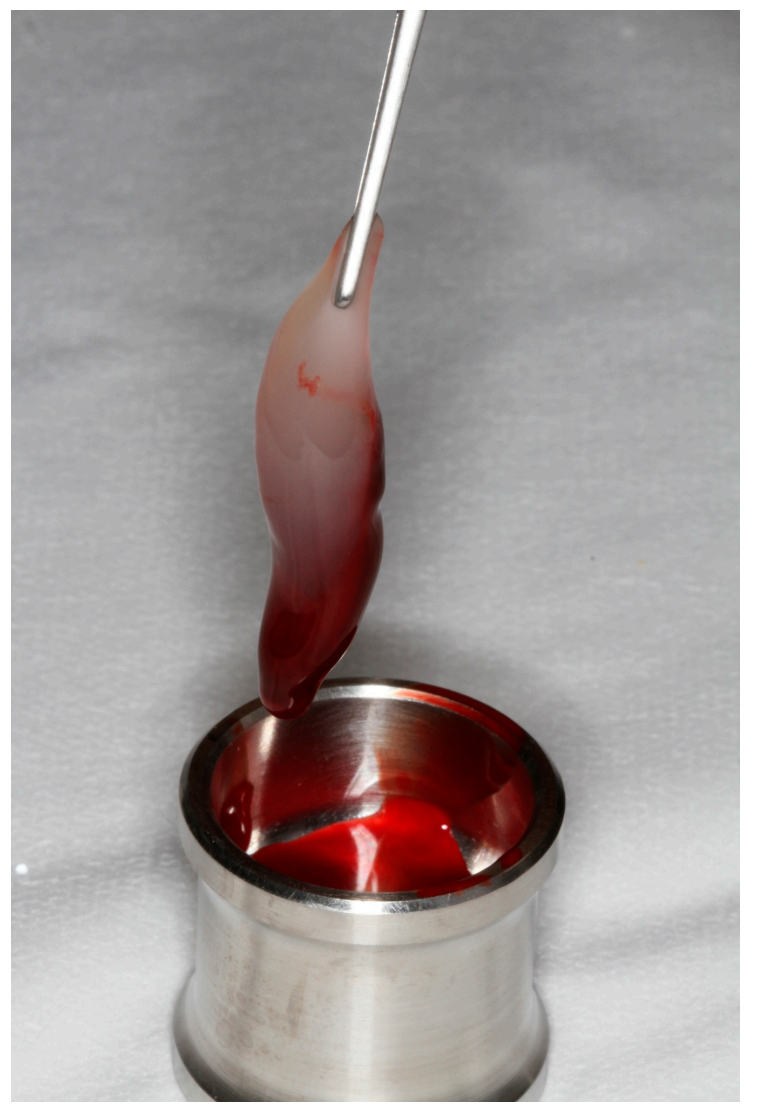

Figure 1. Platelet-rich fibrin (PRF) immediately after removal from the tube.

\subsection{Preparation and Application of $P R F$}

After the general anesthesia of the rabbits (test group), a $10 \mathrm{ml}$ blood sample was collected from the ear vein of each animal with a $40 \times 10$ needle and a $20 \mathrm{ml}$ luer syringe $\left(\mathrm{BD}^{\circledR}\right.$ Sigma-Aldrich Brasil Ltda, 0800-7277292, Sao Paulo, Brazil). The sample tubes without anticoagulant were arranged in the opposite position in the Intra-Spin L-PRF Centrifuge (Intralock, Germany), which was used for $10 \mathrm{~min}$ at a speed of $3000 \mathrm{rpm}$. The fibrin clot was removed from the tube with the aid of clinical tweezers (Figure 2), and after its removal the red portion was separated and discarded and the white portion was left for $10 \mathrm{~min}$ on a perforated metal surface to drain the remaining liquids. Due to the fact that it was a solid material, the obtained PRF was chopped into approximately $3 \mathrm{~mm}$ portions using surgical scissors so that it could be mixed with the particulate xenograft (Figure 3). 


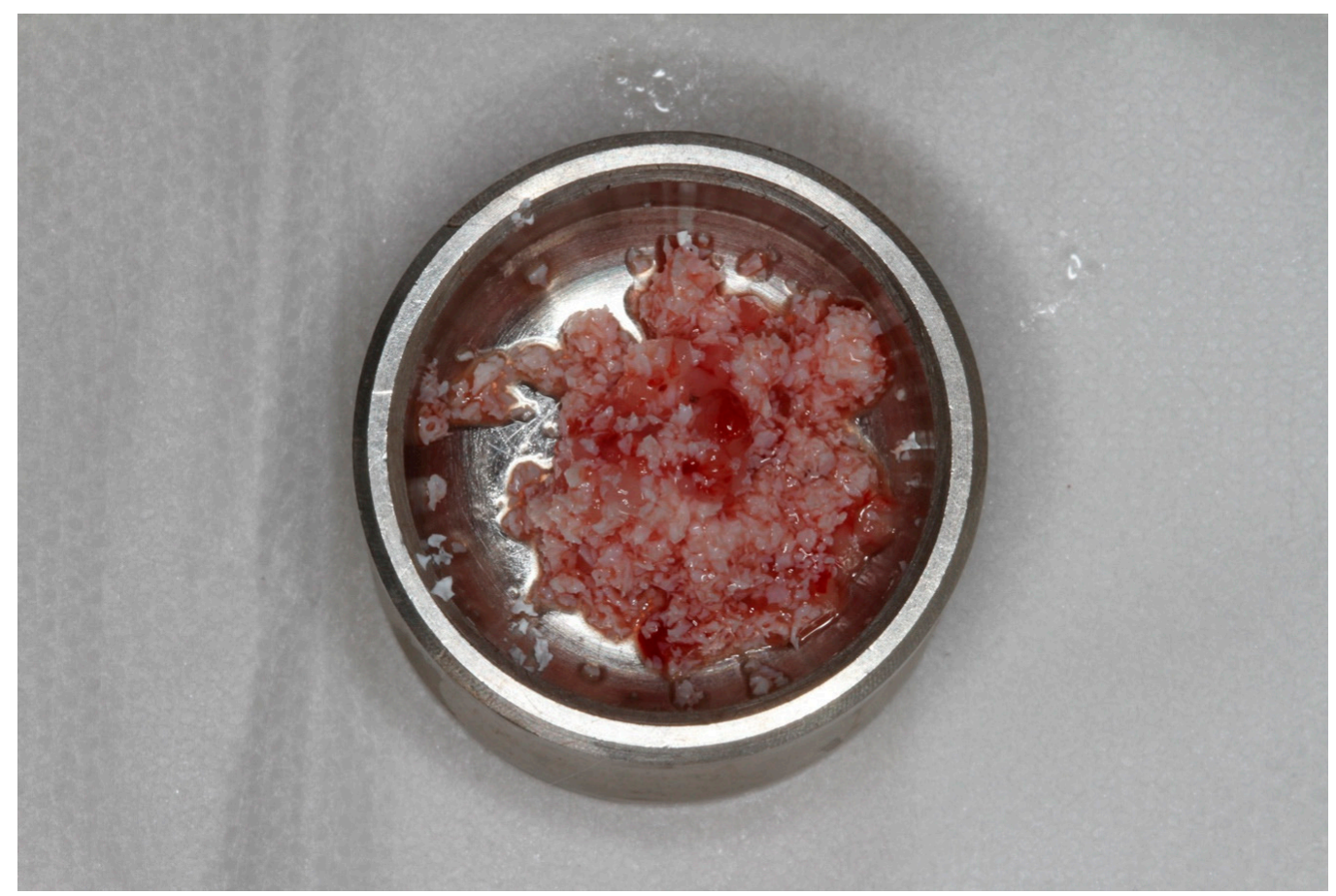

Figure 2. Xenograft mixed with PRF.

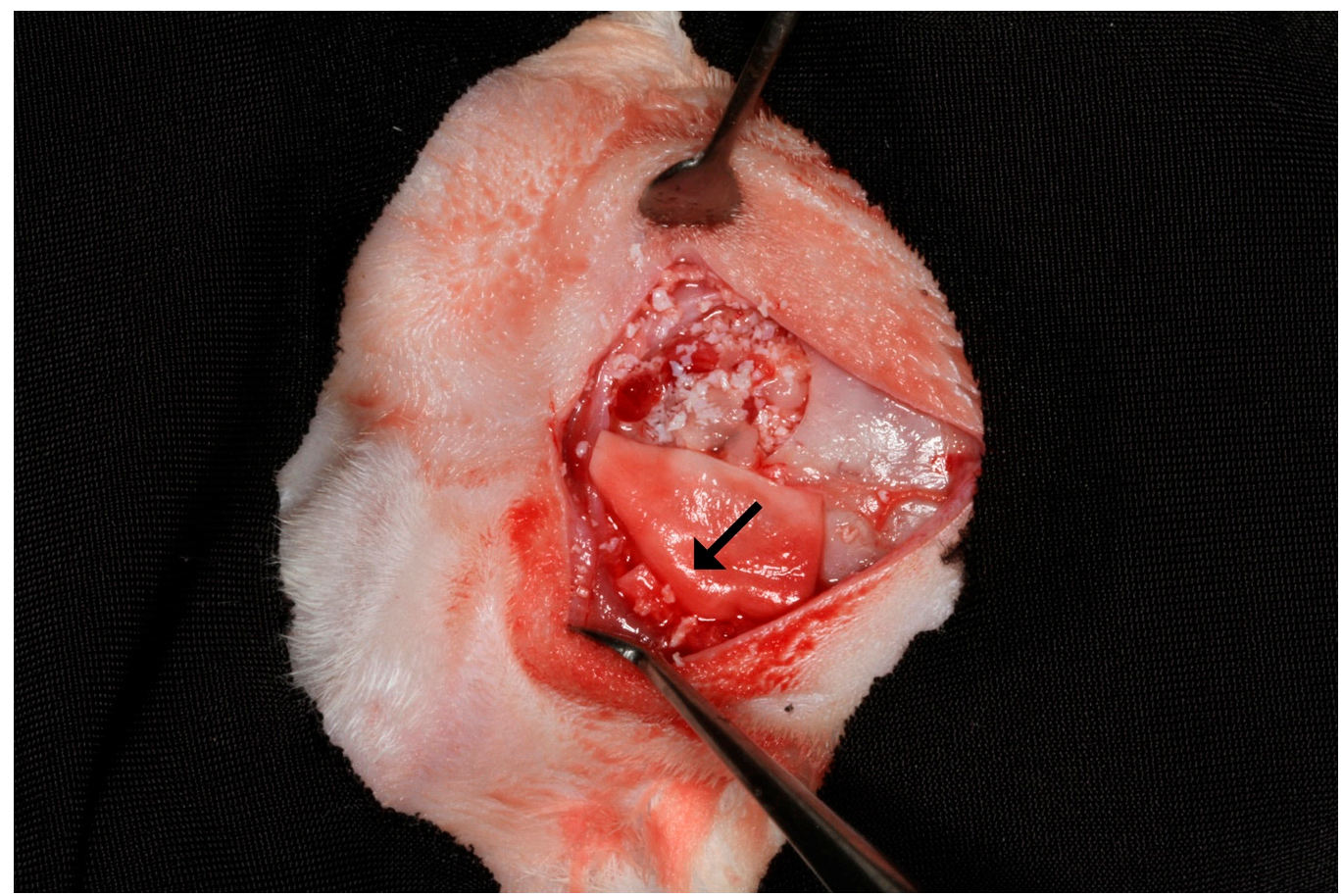

Figure 3. Bone defects filled with the biomaterial covered (rabbit's right side; arrow) or not covered (rabbit's left side) with a barrier membrane.

\subsection{Biopsies Collection}

All animals were euthanized by anesthetic overdose eight weeks after surgery. To collect the parietal bone samples, incision and a mucoperiosteal flap were performed, followed by the removal of approximately $20 \mathrm{~mm}^{2}$ of bone containing the grafted healed area. The osteotomy was performed with a 701 drill (Tri-Hawk, Morrisburg, ON, Canada) adapted to the electric motor handpiece used in the previous phase. 


\subsection{Histologic and Histomorphometric Analysis}

The samples were fixed in $10 \%$ buffered formalin for $48 \mathrm{~h}$. They were then treated with $10 \%$ EDTA solution for decalcification for one hour. Histological analysis was performed on the central portion of the bone biopsies and after histological treatment, $7 \mu \mathrm{m}$ sections of each specimen were obtained and stained with hematoxylin-eosin and examined by light microscopy (Figure 4A,B and Figure 5A,B). Microscopic images were captured using a CCD digital camera (RT Color; Diagnostic Instruments, Sterling Heights, MI, USA). Images were analyzed using Image Pro Plus 4.5 software for Windows (Media Cybernetics, San Diego, CA, USA). The evaluated parameters were: (1) nonvital mineralized tissue (NVMT); (2) vital mineralized tissue (VMT); and (3) nonmineralized tissue (NMT). Connective tissue, bone marrow, blood vessels, and adipose tissue (i.e., all tissues that cannot be considered as a mineralized tissue) were considered NMT. Mineralized tissues (stained in darker pink) were considered vital (VMT) when osteocytes were present and nonvital (NVMT) when osteocytes were absent. All results were measured in $\mu \mathrm{m}^{2}$ and expressed as a percentage of the total area.

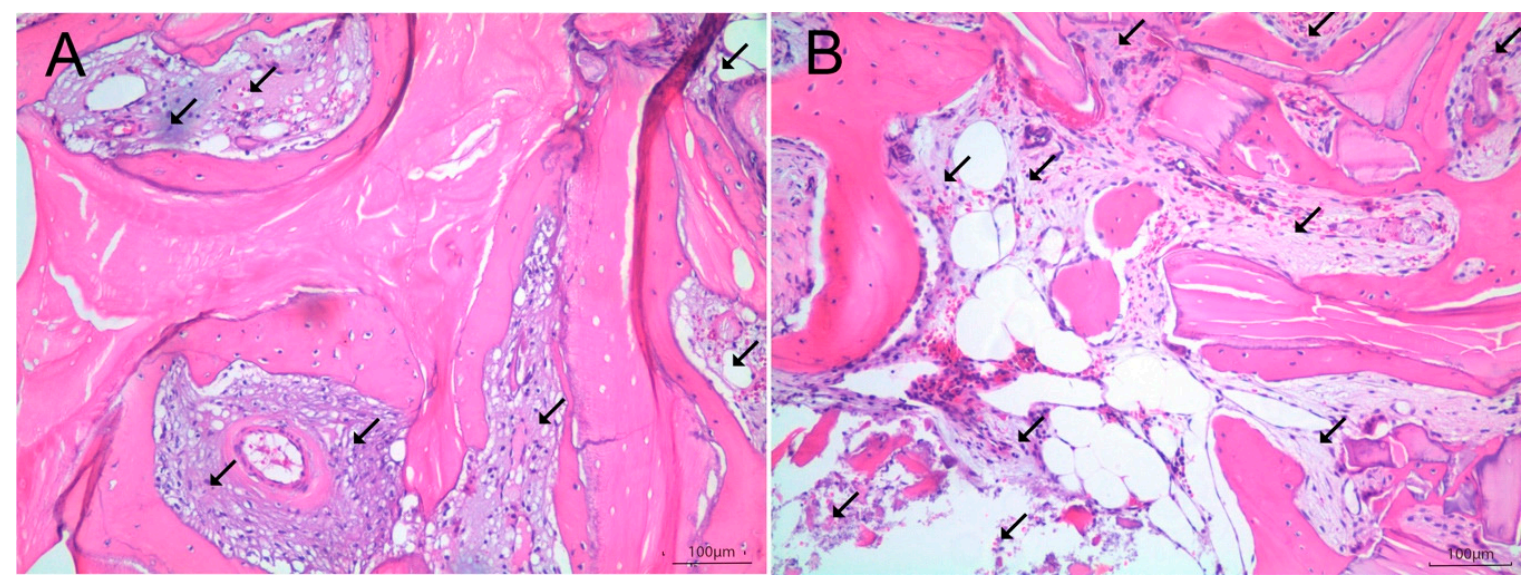

Figure 4. (A) Histological view of a test group subject with membrane coverage specimen (200× magnification). Note the new bone formation in between biomaterial particles and the lower amount of nonmineralized tissue (arrows = nonmineralized tissue). (B) Histological view of a control group subject without membrane coverage specimen (200× magnification). Note the higher amount of nonmineralized tissue (arrows $=$ non mineralized tissue).

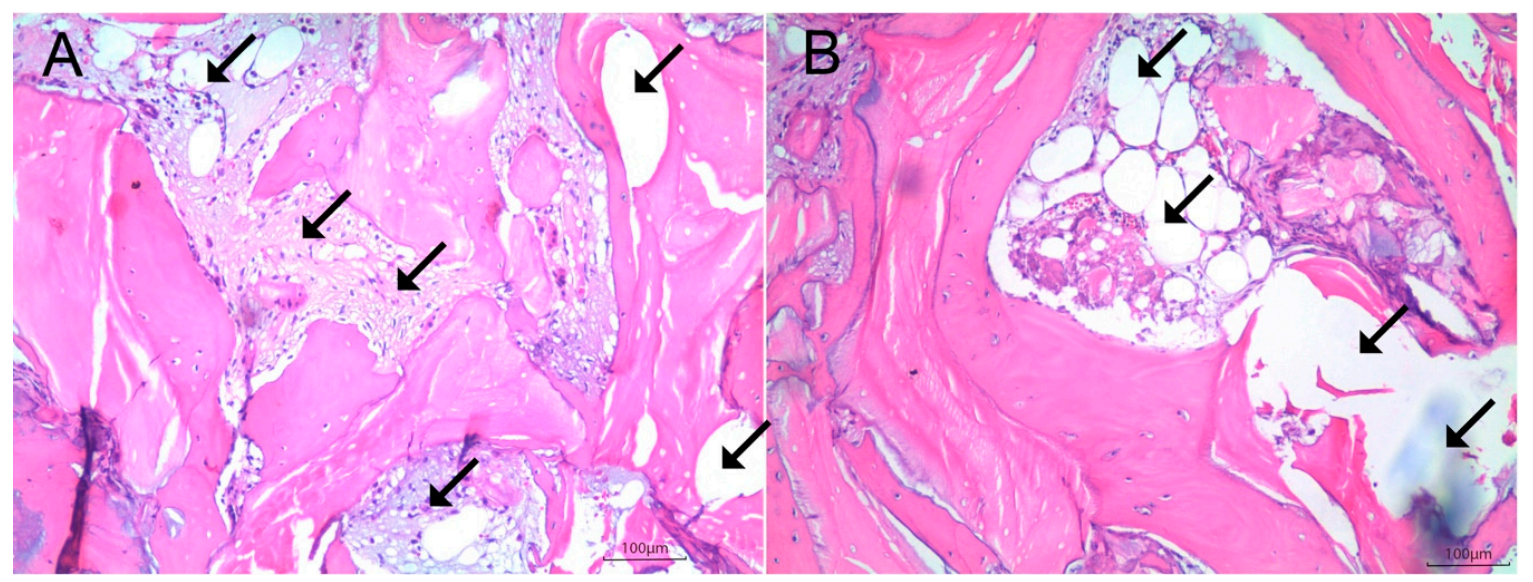

Figure 5. (A) Histological view of a test group subject without membrane coverage specimen $(200 \times$ magnification) (arrows $=$ nonmineralized tissue). (B) Histological view of a control group subject with membrane coverage specimen (200× magnification) (arrows $=$ nonmineralized tissue). Note the similar amount of nonmineralized tissue between the two samples. 


\subsection{Statistical Analysis}

The software SPSS-V17 (SPSS Inc. 233, Chicago, IL, USA) was used to analyze all quantitative data. The Kruskall-Wallis test was used to compare groups for each TMNV, TMV, and TNM variable. The Wilcoxon test was used to compare the results obtained with and without membrane coverage. The value of $p \leq 0.05$ indicated statistical significance.

\section{Results}

\section{Histomorphometry}

Comparing the test and control groups (intergroup comparison) in sites that were covered with collagen membrane, there was no statistically significant difference for all the analyzed parameters. However, when comparing the groups without membrane coverage, a statistically significant difference could be observed for the vital mineralized tissue (VMT) and nonmineralized tissue (NMT) parameters, with more VMT in the test group and more NMT in the control group. Regarding the intragroup comparison, the use of the membrane coverage presented significant outcomes in both groups, with a higher level of VMT and lower level of NMT (Table 1).

Table 1. The results of the histomorphometric analysis.

\begin{tabular}{cccccccc}
\hline \multirow{2}{*}{ Tissue } & \multicolumn{2}{c}{ With Membrane } & \multirow{2}{*}{$p$-Value } & \multicolumn{2}{c}{ Without Membrane } & \multirow{2}{*}{$\boldsymbol{n}$-Value } \\
\cline { 2 - 3 } & Control Group & Test Group & & Control Group & Test Group & \\
\hline NVMT & $13.50 \pm 0.09$ & $17.88 \pm 7.57$ & 0.2971 & & $13.09 \pm 0.06$ & $16.59 \pm 3.54$ & 0.0542 \\
VMT & $13.29 \pm 0.16$ & $13.88 \pm 5.68$ & 0.5211 & & $6.57 \pm 0.08$ & $9.67 \pm 0.60$ & $0.0039 *$ \\
NMT & $73.21 \pm 0.12$ & $68.24 \pm 5.05$ & 0.0776 & & $80.34 \pm 0.05$ & $73.74 \pm 3.48$ & $0.0038^{*}$ \\
\hline
\end{tabular}

Table 1-Inter-group analysis: statistical comparison of mean values (in \%) between the TG $(n=6)$ and CG ( $n=6)$ groups. VMT: vital mineralized tissue; NVMT: nonvital mineralized tissue; NMT: nonmineralized tissue; TG (test group); CG (control group). Statistically significant ${ }^{*}, p \leq 0.05$ (Kruskal-Wallis test).

\section{Discussion}

Autogenous bone grafts are still considered the biological "gold standard" for the reconstruction of critical defects, but the morbidity associated with material collection is the major disadvantage factor. Thus, the search for increased osteogenic capacity of xenogeneic bone substitute biomaterials has been verified in several preclinical and clinical studies $[7,8,15]$. These studies were conducted to contribute with scientific evidence that xenogeneic biomaterials, although acellular, could acquire osteogenicity when associated with biological tissues and/or cells, and not just osteoconduction [16]. Therefore, some highly cellularized biological tissues, such as fresh and centrifuged bone marrow, as well as bone marrow and adipose tissue stem cells, have been associated with xenogeneic bone grafts to analyze the amount of vital mineralized tissue (VMT), that is, the newly formed bone, in experimental animal models-more specifically, models of critical defects in rabbit calvaria, similar methodology to that used in this study $[7,8,17]$. Such studies have shown results of increased amount of newly formed tissue due to the association of fresh biological tissue or the use of adult mesenchymal stem cells with xenogeneic biomaterial. However, despite promising published results, a relevant problem still lies in the degree of morbidity associated with bone marrow collection, in addition to its preparation, which must be performed within a hospital environment, increasing the cost and working time [8]. In contrast, the use of venous blood products has some advantages, such as easy collection, low cost, and possibility of being performed in a clinic environment [18]. Platelet-rich fibrin (PRF) is a peripheral blood derivative obtained by centrifugation and consists of a dense matrix of fibrin, rich in growth factors, leukocytes, and adhesive proteins, important in the healing process, accelerating vascularization and subsequent tissue regeneration. Despite these relevant properties, the isolated use of PRF has not shown significant results in previous studies, which is major reason the present study 
used it in combination with a mineralized xenogeneic biomaterial in critical defects in rabbit calvaria, a methodology that had not yet been verified with caution in the literature with the use of PRF.

Based on methodology previously published in an experimental animal model by Pelegrine et al. (2014) [7] and Aloise et al. (2015) [8], in this study we decided to use a porcine collagen membrane to cover one of the two critical defects produced in animal calvaria, with the intention of establishing an analysis from the perspective of guided bone regeneration [19]. Thus, it was possible to establish correlations between the usage, or not, of PRF, as well as the use, or not, of collagen membrane (i.e., guided bone regeneration concept). In this study the values for VMT in the control group (CG) and test group (TG) on the side without the membrane coverage were $6.56 \% \pm 0.08 \%$ and $9.52 \% \pm 0.60 \%$, respectively, with statistical difference $(p<0.05)$. Values for the membrane-covered side were $13.29 \% \pm 0.16 \%$ and $13.88 \% \pm 5.68 \%$ respectively for CG and TG, with no statistical difference $(p>0.05)$. For NMT, the values for the control group (CG) and test group (TG) on the side without the membrane cover were $80.34 \% \pm 0.05 \%$ and $73.74 \% \pm 3.48 \%$, respectively, with statistical difference $(p<0.05)$. Values for the membrane-coated side were $73.21 \% \pm 0.12 \%$ and $68.24 \% \pm 5.05 \%$, respectively, with no statistical difference between them $(p>0.05)$. The level of NMT was higher in CG without membrane coverage and lower in TG with membrane coverage, which can be clearly noticed in Figures 4 and 5 . These results demonstrate that the addition of PRF cell components to particulate bone grafts allows an increase in the amount of newly formed bone and a decrease in nonmineralized tissues, only when a membrane related to the guided bone regeneration technique is not used. However, when the membrane was used, the usage of PRF did not reflect any change in the mineralization pattern, corroborating the findings of Bolukbasi et al. (2015) [13]. A possible hypothesis for this finding is that PRF in the control group may have performed some bioactive barrier function to peripheral fibroblasts, but without overcoming the barrier role of the collagen membrane used in this study. Therefore, it is important to state that the membrane technique may be the choice used in therapeutics.

When the values of VMT obtained in this study are compared with the results obtained by Aloise et al. (2015) [8] and Pelegrine et al. (2014) [7], who made use of the same experimental model of the present study (i.e., critical bone defect produced in rabbit calvaria), the values of this study are lower. This may indicate that the stimulation caused by PRF is less than that generated by fresh bone marrow, centrifuged bone marrow, and bone marrow stem cells, which may be linked to the fact that bone marrow and bone marrow-derived stem cells have higher affinity for bone tissue than venous blood cells used for PRF production. In this study, the analysis of the amount of nonvital mineralized tissue (NVMT), which represents the residual particles of the xenogeneic graft, showed no statistical difference between CG and TG, with or without collagen membrane coverage. This shows that the level of resorption of xenogeneic graft has not significantly changed, regardless of whether or not the concept of guided bone regeneration was used. This finding may be related to the fact that the biomaterial used in this study was a bovine hydroxyapatite, which presents a very slow resorption pattern [20]. However, it is reasonable to consider that in the test group, probably, the amount of bovine hydroxyapatite used was smaller, since PRF seems to occupy significant volume between bone particles (data not shown).

\section{Conclusions}

Based in this experimental model we can conclude that:

(1) Platelet-rich fibrin does not result in higher levels of bone formation when a guided bone regeneration technique (i.e., with membrane coverage) is used.

(2) The usage of the collagen membrane has a synergistic effect on bone healing when associated with a xenograft.

(3) Platelet-rich fibrin may increase the level of newly formed bone only in bone grafting procedures using xenograft without collagen membrane coverage. 
Author Contributions: Conceptualization, P.W.M. and A.C.A.; data curation M.L.T. and A.A.P.; formal analysis P.W.M. and A.C.A.; funding acquisition, M.L.T. and A.A.P.; investigation P.W.M. and A.A.P.; methodology, P.W.M. and A.A.P.; project administration A.C.A. and L.G.S.d.M.; resources M.L.T. and C.A.P.J.; software, P.W.M., J.M.A., and L.G.S.d.M.; supervision M.L.T. and J.M.A.; validation, J.L.C.-G. and J.M.A.; visualization A.C.A. and A.A.P.; writing-original draft preparation, A.A.P. and J.M.A.; writing-review and editing J.L.C.-G. and A.A.P.

Funding: This research received no external funding.

Conflicts of Interest: The authors declare no conflict of interest.

\section{References}

1. Chrcanovic, B.; Albrektsson, T.; Wennerberg, A. Bone Quality and Quantity and Dental Implant Failure: A Systematic Review and Meta-analysis. Int. J. Prosthodont. 2017, 30, 219-237. [CrossRef] [PubMed]

2. Bagher, Z.; Rajaei, F.; Shokrgozar, M. Comparative Study of Bone Repair Using Porous Hydroxyapatite/ $\beta$-Tricalcium Phosphate and Xenograft Scaffold in Rabbits with Tibia Defect. Iran. Biomed. J. 2012, 16, 18-24. [PubMed]

3. Stevenson, S.; Emery, S.E.; Goldberg, V.M. Factors Affecting Bone Graft Incorporation. Clin. Orthop. Relat. Res. 1996, 324, 66-74. [CrossRef] [PubMed]

4. Gultekin, B.A.; Bedeloglu, E.; Kose, T.E.; Mijiritsky, E. Comparison of Bone Resorption Rates after Intraoral Block Bone and Guided Bone Regeneration Augmentation for the Reconstruction of Horizontally Deficient Maxillary Alveolar Ridges. BioMed Res. Int. 2016, 2016, 4987437. [CrossRef] [PubMed]

5. Titsinides, S.; Agrogiannis, G.; Karatzas, T. Bone grafting materials in dentoalveolar reconstruction: A comprehensive review. Jpn. Dent. Sci. Rev. 2019, 55, 26-32. [CrossRef] [PubMed]

6. De Lacerda, P.E.; Pelegrine, A.A.; Teixeira, M.L.; Montalli, V.A.M.; Rodrigues, H.; Napimoga, M.H. Homologous transplantation with fresh frozen bone for dental implant placement can induce HLA sensitization: A preliminary study. Cell Tissue Bank. 2016, 17, 465-472. [CrossRef] [PubMed]

7. Pelegrine, A.A.; Aloise, A.C.; Zimmermann, A.; de Mello E Oliveira, R.; Ferreira, L.M. Repair of critical-size bone defects using bone marrow stromal cells: A histomorphometric study in rabbit calvaria. Part I: Use of fresh bone marrow or bone marrow mononuclear fraction. Clin. Oral Implant. Res. 2014, 25, 567-572. [CrossRef] [PubMed]

8. Aloise, A.C.; Pelegrine, A.A.; Zimmermann, A.; Oliveira, R.D.M.E.; Ferreira, L.M. Repair of critical-size bone defects using bone marrow stem cells or autogenous bone with or without collagen membrane: A histomorphometric study in rabbit calvaria. Int. J. Oral Maxillofac. Implant. 2015, 30, 208-215. [CrossRef] [PubMed]

9. Pasquali, P.J.; Teixeira, M.L.; De Oliveira, T.A.; De Macedo, L.G.S.; Aloise, A.C.; Pelegrine, A.A. Maxillary Sinus Augmentation Combining Bio-Oss with the Bone Marrow Aspirate Concentrate: A Histomorphometric Study in Humans. Int. J. Biomater. 2015, 2015, 121286. [CrossRef] [PubMed]

10. De Oliveira, T.A.; Aloise, A.C.; Orosz, J.E.; Oliveira, R.D.M.E.; De Carvalho, P.; Pelegrine, A.A. Double Centrifugation Versus Single Centrifugation of Bone Marrow Aspirate Concentrate in Sinus Floor Elevation: A Pilot Study. Int. J. Oral Maxillofac. Implant. 2016, 31, 216-222. [CrossRef] [PubMed]

11. Chieruzzi, M.; Pagano, S.; Moretti, S.; Pinna, R.; Milia, E.; Torre, L.; Eramo, S. Nanomaterials for Tissue Engineering in Dentistry. Nanomaterials 2016, 6, 134. [CrossRef] [PubMed]

12. Dohan, D.M.; Choukroun, J.; Diss, A.; Dohan, S.L.; Dohan, A.J.; Mouhyi, J.; Gogly, B. Platelet-rich fibrin (PRF): A second-generation platelet concentrate. Part I: Technological concepts and evolution. Oral Surg. Oral Med. Oral Pathol. Oral Radiol. Endodontol. 2006, 101, e37-e44. [CrossRef] [PubMed]

13. Bolukbasi, N.; Ersanli, S.; Keklikoglu, N.; Basegmez, C.; Özdemir, T. Sinus augmentation with platelet-rich fibrin in combination with bovine bone graft versus bovine bone graft in combination with collagen membrane. J. Oral Implant. 2015, 41, 586-595. [CrossRef] [PubMed]

14. Borie, E.; Oliví, D.G.; Orsi, I.A.; Garlet, K.; Weber, B.; Beltrán, V.; Fuentes, R. Platelet-rich fibrin application in dentistry: A literature review. Int. J. Clin. Exp. Med. 2015, 8, 7922-7929. [PubMed]

15. Pelegrine, A.A.; Teixeira, M.L.; Sperandio, M.; Almada, T.S.; Kahnberg, K.E.; Pasquali, P.J.; Aloise, A.C. Can bone marrow aspirate concentrate change the mineralization pattern of the anterior maxilla treated with xenografts? A preliminary study. Contemp. Clin. Dent. 2016, 7, 21-26. [CrossRef] [PubMed] 
16. Lucarelli, E.; Beretta, R.; Dozza, B.; Tazzari, P.; O'Connell, S.; Ricci, F.; Pierini, M.; Squarzoni, S.; Pagliaro, P.; Oprita, E.; et al. A recently developed bifacial platelet-rich fibrin matrix. Eur. Cells Mater. 2010, 20, 13-23. [CrossRef]

17. Zimmermann, A.; Pelegrine, A.A.; Peruzzo, D.; Martinez, E.F.; Oliveira, R.D.M.E.; Aloise, A.C.; Ferreira, L.M. Adipose mesenchymal stem cells associated with xenograft in a guided bone regeneration model: A histomorphometric study in rabbit calvaria. Int. J. Oral Maxillofac. Implant. 2015, 30, 1415-1422. [CrossRef] [PubMed]

18. Nacopoulos, C.; Dontas, I.; Lelovas, P.; Galanos, A.; Vesalas, A.-M.; Raptou, P.; Mastoris, M.; Chronopoulos, E.; Papaioannou, N. Enhancement of Bone Regeneration with the Combination of Platelet-Rich Fibrin and Synthetic Graft. J. Craniofacial Surg. 2014, 25, 2164-2168. [CrossRef] [PubMed]

19. Yoon, J.-S.; Lee, S.-H.; Yoon, H.-J. The influence of platelet-rich fibrin on angiogenesis in guided bone regeneration using xenogenic bone substitutes: A study of rabbit cranial defects. J. Cranio-Maxillofac. Surg. 2014, 42, 1071-1077. [CrossRef] [PubMed]

20. Pistilli, R.; Felice, P.; Piatelli, M.; Nisii, A.; Barausse, C.; Esposito, M. Blocks of autogenous bone versus xenografts for the reha- bilitation of atrophic jaws with dental implants: Preliminary data from a pilot randomised controlled trial. Eur. J. Oral Implantol. 2014, 7, 153-171. [PubMed]

(C) 2019 by the authors. Licensee MDPI, Basel, Switzerland. This article is an open access article distributed under the terms and conditions of the Creative Commons Attribution (CC BY) license (http://creativecommons.org/licenses/by/4.0/). 